\title{
The investigation of key factors for successful implementation of sustainable halal food supply chain management
}

\author{
*Azhar, A. and Tu, Y.T. \\ Department of Business Administration, College of Management, Asia University, Taichung, Taiwan
}

\author{
Article history: \\ Received: 3 April 2021 \\ Received in revised form: 11 \\ May 2021 \\ Accepted: 10 June 2021 \\ Available Online: 19 \\ December 2021
}

\section{Keywords:}

Halal food supply chain,

Sustainability,

SAS Text Miner

DOI:

https://doi.org/10.26656/fr.2017.5(6).235

\begin{abstract}
Halal food plays an important role in the economic development in various countries. However, halal food supply chains could threaten the environment in several ways. This study was aimed to analyse the best practice of the implementation of a sustainable halal food supply chain from many data sources. The data then transform into managerial knowledge for the halal food industry. The data was collected using SAS Text Miner and analyzed using the decision tree. The analysis shows four key features of sustainable halal food supply chains: pre-slaughtering, warehousing, halal integrity, and packaging. From these features, the two most important factors of successful sustainability implementation in the halal food supply chain are found to be warehousing and packaging. The present study applies a relational view theory and an analysis theory of natural resource-based view, creating and extending new sustainable strategies of halal food chain management to sustainable halal food chain management.
\end{abstract}

\section{Introduction}

Customers' needs can be met through a wellestablished food supply chain (La Scalia et al., 2017). Elements in the food supply chain can rot quicker than the conventional supply chain (Chen et al., 2008). Consequently, food supply chains need further administration to ensure the protection of goods, as flexible food supply chains need (Leat and RevoredoGiha, 2013). With global climate change, water use, water spray and natural disruptions in mind, the expanding market for food combined have gradually increased the importance of sustainability to the halal food industry (Benis and Ferrão, 2017). These sustainability hurdles have placed enormous pressure on the food sector. A comprehensive solution to reduce gas exhaust flows in the food supply chain is expected by Camanzi et al. (2017). Assist considers on a way to oversee food supply chains successfully in a maintainable way are required on the preface of the serious impacts of food supply on environmental sustainability.

Halal food supply chain partners share a good understanding of natural endurance but are not aware of how this goal is achieved in the nearness of a vast body of research that can shed light on their support decisions. In other words, companies that need to go green can choose from a number of options to expand to manage limited assets. Moreover, one of the features of the calculation motivates the current opinion: discrete data are usually more accurate than international forecasts (Chopra and Meindl, 2007). Thus, this study reviews past cases of the halal food chain to recognize the core common components for businesses to achieve sustainability in this sector.

The halal food industry, other than being financially and socially vital, current frameworks of food production, distribution, and utilization have a critical effect on natural debasement, causing consumption of normal assets, weakening of environments, social wellbeing and jobs (Nuhoff-Isakhanyan et al., 2016). Food supply chains are mindful of a huge share of household-related natural impacts, including 29\% of nursery gas (GHG) outflows, 58\% of eutrophication, $30 \%$ of fermentation and $32 \%$ of ecotoxicity (Barratt, 2004). In expansion, partners progressively anticipate companies to oversee and unveil natural and social impacts as prove of successful corporate administration, subsequently, speculators will be appearing intrigued by how the food segment is reacting to maintainability challenges. Reacting to sustainability issues, halal and sustainability are presently both seen as openings to making strides. It is now not sufficient for makers to centre exclusively on what sort of food is delivered, how nourishment is created fairly and critically. As well as item fixings, shoppers all over are progressively 
concerned about cultivating creature welfare, transport, bundling, and squander administration, and numerous are requesting nutritious and quality food alternatives that permit them to lead a more advantageous way of life. By joining green practices in the halal food supply chain gives an opportunity, in case way better caught on, to progress the numerous angles of halal generation, in this way contributing towards more maintainable and secure nourishment future (Karia and Asaari, 2016). Halal is not essentially an expression of challenging shapes of production and consumption. It is part of a quickly extending, globalized advertisement beginning to bring the concerns to Muslim and non-Muslim buyers closer together.

This study leads to an overview of the fundamental components of the worldwide halal food supply chains in real, sustainable halal food supply chains, and identifies crucial positive factors for sustainable halal food supply chains. In expansion, feasible halal food supply chain arrangements are outlined to guarantee that decisionmakers proficiently give constrained assets to their halal food business.

The key contributions of this research can be summarized as the fundamental establishment produces business analysis that methodically extracts data and best practices from unstructured textual data relating to sustainable halal food supply chains with a primary objective of promoting successful sustainability execution by enterprises. Especially the main genuine situations, like halal food supply chains, are excluded from unique dynamic data aggregations, that the operating systems of multiple organizations and situations can be properly understood. In the sense of an overwhelming variety of maintenance solutions, this consideration reveals a critical evaluation of the right options based on the optimistic decisions taken in the past by businesses as green. In addition, Relational View (RV) and Natural Resources Based View (NRBV) theories are widely used in various fields, although they have been used by few to ask about the economical supply chains of halal foods. In this manner, both RV and NRBV are integrated into the experimental discoveries of the proposed commerce analytics to supply important approaches for accomplishing economical management of the halal food supply chain and to counterpoint both speculations themselves. Also, the proposed examination offers crucial data on how complex literary information may be changed over into valuable bits of knowledge for sustainable halal food supply chain management (SCM).

\section{Materials and methods}

\subsection{Data collection}

The present research has included selected websites for halal food supply chains to incorporate fundamental knowledge of food supply chains management. A watchword look is often used to extract unstructured text data from interpersonal websites (Figure 1).

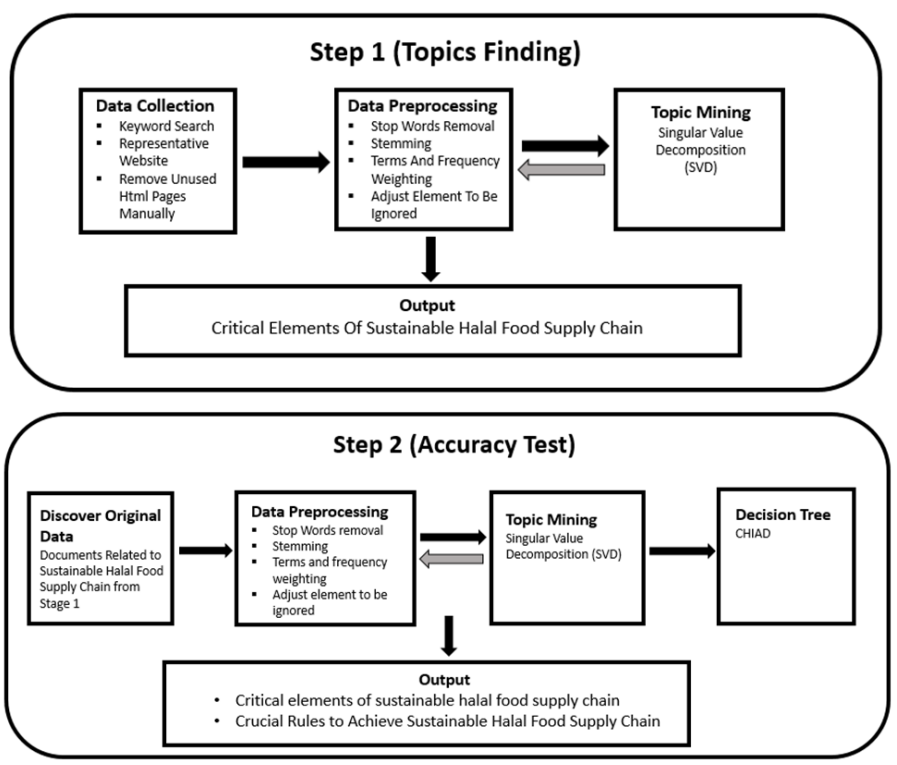

Figure 1. The steps of analytics for halal food supply chain management.

\subsection{Data preprocessing}

The main move in the processing of documents is to represent documents for successful document classification (Oliveira and Seok, 2005). This research uses pre-processing techniques such as tokenization, halting word exclusion and stemming. Tokenization is the way that a stream of text information is broken into tokens, which may be expressions, terms, phrases or symbols. For further analysis, such as sorting or text mining, the token list is stored in input. Most of them appear frequently in texts, but they are meaningless terms since the words are connected in a single sentence. Stop words are generally accepted and do not denote the substance or purpose of text papers. It is known as stemming that combines various forms of a word with a typical example (Porter, 1980). The most common word appears around hours as often as the $\mathrm{h}$ most often occurring word (Gerlach and Altmann, 2013).

$$
f(h)=\frac{f(1)}{h}
$$

Identifying the various morphological terms that map different forms onto some common form, specifically removing suffixes, is a crucial step in text mining. To reliably extract matching stems, this study used dictionary-based stemming (Brants, 2003). After stemming, synonyms that merged into one word were identified. 
The value of each word in a document is then examined using a term-frequency matrix. Term frequency matrix is made up of words (row) and documents (column) (column). The number of times each word appears in a document is expressed by a matrix entry. The word and frequency weights can be calculated using equation (2). The function $y$ (.) denotes the weighted frequency of terms; $q_{i, j}$ denotes the $i j$ th frequency in the unweighted word-frequency matrix; $w_{i}$ denotes the weight of the ith term $i$ th term.

Term and frequency weight $=w_{i} x y\left(q_{i, j}\right)$

For the raw term inputs, this analysis uses log transformation to achieve frequency weight, as seen in equation (3) (Mashechkin et al., 2011; Karl et al., 2015). High-frequency words will reduce log change to dominate overall results.

$$
y\left(q_{i, j}\right)=\log _{2}\left(q_{i, j}+1\right)
$$

This research adopts entropy to gain term weight as set out in equation (4) (Mashechkin et al., 2011). In this part, $\mathrm{N}$ is the total number of corpus documents.

$$
w_{i}=1-\sum_{j}^{N} \frac{\left(\frac{q_{i j}}{h_{i}}\right) x \log _{x}\left(\frac{q_{i j}}{\hbar_{i}}\right)}{\log _{2} N} \text {, where } h_{i}=\sum_{k=1}^{N} q_{i, k}
$$

In pre-processing data, we also proposed the adaptation of elements to make sure the cleanest data are essential elements as the performance.

\subsection{Topic mining}

Unexpressed subjects distinguish between similar usage of words and use of words with different implications. A pivoting, specific estimation decay can also be used to win points (Chen et al., 2008; Alghamdi and Alfalqi, 2015; Kou and Peng, 2015). Singular decay is also linked to the extraction unit and is used for breaking a grid in a useful manner for reducing its dimensionality. Equations (5) and (6) can be used to characterize singular value decay (6). The unit of three frames constructs the term-by-record $\mathrm{X}$ as follows: $\mathrm{X}$ means an mn frame of rank $\mathrm{k}$; $\mathrm{S}$ means a $\mathrm{k} \mathrm{k}$ incline with solitary values; $\mathrm{W}$ corresponds to the $\mathrm{m} \mathrm{k}$ scheme of orthogonal columns; $\mathrm{V}$ means a $\mathrm{k} n$ grid. The measurement of the original $\mathrm{Xr}$ frame is done by protecting the greatest specific values. The new matrices (Wr, Sr and VT r) refer to a comparative column decrease of the W, S and VT matrices (Karl et al., 2015; Kou and Peng, 2015; Zhai and Massung, 2016).

$X=W S V^{T}$

$X_{r}=W_{r} S_{r} V_{r}^{T}$

\subsection{Decision tree}

In this article, initial text data on sustainable halal food supply chains is manually searched and arranged.
The proposed model decision tree used mining as an input for the procurement of critical components of the sustainable halal food supply chain. Moreover, to determine whether a sustainable halal food supply chain can be accomplished in an organizational scenario, the target feature of the decision boom model is "efficiency." A good sustainable halal food supply chain has a beneficial effect on the long-term survival of the environment.

\subsection{Analytical result}

Using the data gathered, the proposed analytics explored crucial insight into the general supply chains of halal food and safe halal supply chains.

\section{Results and discussion}

\subsection{Analytical results of overall food supply chains}

Unstructured textual data concerning the halal supply chains were collected from representative websites, such as ScienceDirect, Web of Science and Researchgate dating back to 2010 and 2020 through keyword searches, including the halal food supply chain, the halal food distribution and halal food transportation. A total of 1021 articles have been collected initially. Some researchers have used SAS Business Guide 7.1 to delete redundant documents but this is not a flawless function, and each record left was manually checked in order to ensure no repetition. In this research, we proposed removing unused HTML pages manually technique to clean the data in the first step to crawl the data from the website. We use two steps to make sure the validity of the data.

The text was subsequently categorized into the major parts of the language by SAS Text Miner 14.1, which included nouns rather than the right nouns or noun groups (2015) or verbal adjectives (2642), adjectives (1869), proper nouns (4189), adverbs (282) and noun classes (2650). (5). Afterwards, the software has made a blacklist and synonymous lists to prevent potential noise (SAS Institute Inc. 2016). In SAS Text Miner 14.1 the subject mining feature was performed to detect the main subjects of halal food supply chains. To obtain a satisfactory result, the above procedure should be continuously carried out.

Around four topics on halal food chain were discussed in the analytical results of the topic mining: pre-slaughtering, warehousing, halal integrity, and packaging. Such four topics may be used as clues for recovering from original unstructured records significant cases of food supply chains. 


\subsubsection{Pre slaughtering}

The pre-slaughter process includes any operation related to the rearing and fattening of livestock. Halal meat production is distinguished by the inclusion of halal livestock feeding and the control of animal health on the farm from any other food category. Any animal diseased or infected should be removed from the cattle and farmers must maintain a medical record of their livestock throughout the rising period as regards disease, veterinary diagnosis and care outcomes (Wang, 2015). In addition, all medical procedures and vaccinations containing pork enzymes are unfit for eating and render animals non-halal. Livestock farms should be protected and not within the proximity of pig farms or off-farm pig farms (Soon et al., 2017). It is also worth mentioning that halal animals become haram during breeding if the animals are supplied with any product derived from haram sources or obtained biotechnologically through genetic engineering using the ingredients and components of the haram species. In doing so, halal would be humane to animals (i.e. safe from epidemics, diseases and injuries) and environmentally friendly, as well as nutritious and organic. As a consequence, how livestock is treated, reared and fattened is the main consideration to ensure that animal health is protected and that the first phase of the supply chain structure conforms with the halal guidelines.

\subsubsection{Warehousing}

The logistics management facilities, such as the halal storage facility, play an important role in the successful history of the halal sector through the maintenance of the standard of halal products (Tan et al., 2012). It has been stated (Alam and Mohamed Sayuti, 2011) that whether the products are properly distilled or stored, they are not considered halal. The literature also notes that if halal vendors do not alter the activities of the halal supply chain of their supply chain, they will doubt their halal status. It means liability for the halal warehouse which is completely engaged in the Halal supply chain management. As halal goods tend to grow in market value, so does also the number of companies accredited as halal suppliers.

\subsubsection{Halal integrity}

The word "food integrity" is intended to be used to identify foods that are described correctly for the very things they are (Manning and Soon, 2014). Halal honesty will then once again explicitly indicate specifics of the product's halal status and ensure that the conditions relating to halal as set out are fulfilled. Transparency is essential in order for customers to make educated choices to enhance halal credibility in foreign trade
(Farouk et al., 2016).

\subsubsection{Packaging}

Containing and protecting the products during supply and shipment is the task of packing in logistics. It is often used to shield staff when processing chemical, liquid or loose materials. Additionally, packaging removes or decreases the risks that the logistic operation will entail injury, spoilage, misplacement and robbery. Packaging prevents goods from halal- and nonhalalsubstances cross-contamination in the spirit of halal. In addition, the covering is often used to tamp the halal mark, so that the halal status remains intact. Packing for the separation of halal and nonhalal products by the application of various carriers or separate compartments on the same carrier during transport and distribution.

\subsection{Analytical results of sustainable halal food supply chains}

This research identified the initial unstructured data in order to retrieve environmental sustainability papers in order to better understand the environmental sustainability of halal food supply chains. 110 Halal Food SCM documents concerning environmental sustainability were collected out of 412 initial unstructured documents and Html files (after data preprocessing). In addition, to the 110 HFSCM documents, successful halal food supply chain operations are being read and twice reviewed. 65 articles mentioning successful supply chains for halal food were treated as 1 (subsequent operations), while 45 other publications had been considered as 0 in the decision tree model's 'success' goal attribute. One of the initial unstructured data collections shows that in Indonesia, many food firms had eliminated waste and hazardous materials successfully and implemented a 100\% recycled design, recycle, disassembly and reuse design, materials reuse and recycling, box cuts, and recyclable/reusable packages (Al-Ghwayeen and Abdallah, 2018). This finding was assigned a mark of one in the performance attribute. The main themes were drawn up using the topic mining from 110 food SCM documents concerning environmental sustainability. The subject matter of the mining review disclosed the following four issues: processing, warehousing, halal storage and transport as well as packaging.

\subsubsection{Halal processing}

The halal food's wholesomeness is a major determinant of consumption patterns (Bonne et al., 2007; Zulfakar et al., 2014; Ali et al., 2017). Halal food is produced in a different way than traditional food. Halal food production is based on four additional requirements. For instance, neither food nor additives should be 
obtained from non-halal animals or halal animals that were not killed under Islamic rule. Second, slaughter should take care of the health of the animal in compliance with Islamic law. Third, no dirt contamination can occur. The ultimate prerequisite is to be clean and safe to consume refined food and its ingredients, not dangerous, poisonous and safe to health.

\subsubsection{Warehousing}

Since Halal items spend longer in warehousing, which is the place where producers store their goods before delivering them. The supply chain is clean and halal from farm to fork. It is like the Halal transport concept, which distinguishes halal and non-halal passengers.

\subsubsection{Halal storage and transportation}

With the exception of the ultimate purpose of hala transportation being to maintain halal dignity, such measures can also help to save resources and materials by implementing more stringent standards on emissions and fuel usage, allowing for better regulation (Ali and Suleiman, 2016). The advantages of halal food storage, transportation, show, sale, and serving for long-term production are clear.

\subsubsection{Packaging}

The halal standards also apply to food packaging, where the products must be made from halal elements (for example, direct interaction with hazardous materials is prohibited) ( $\mathrm{Ab}$ Talib and Mohd Johan, 2012). The addition of a halal $\log 0$ to the label is also needed. Furthermore, even the promotion of halal food should not violate Islamic law (e.g. advertising with the use of indecent pictures). These two components, nonhazardous packaging and marketing restrictions, can be seen as aligning with sustainable consumption trends.

Two critical factors were established from the effective halal food supply chain classification model: warehousing and packaging, as shown in Table 1. Warehousing and packaging in particular are the critical factors that determine healthy halal food supply chains with environmental security. As consequent neglect on the environmental sustainability efficiency of the halalfood supply chain: halal storage and transportation and halal processing, the following input attributes were omitted from the decision-tab model. Table 2 summarizes three classification rules developed based on the decision tree model for reliable, environmentally sustainable food supply chains.

To achieve moderate to low environmental protection the critical factors impacting the performance of halal food supply chains are: warehousing and packing. In other words, the most important dividing characteristics for the Halal food chain model were decided during the splitting of the decision tree. Efficient warehouse management is more likely to contribute to sustainable supply chains for halal food (Scheme 1 in Table 2). The prevailing topic of warehousing in halal food supply chains should be given more consideration by Halal companies. In addition, the packaging would contribute more to the target of sustainable food supply chains (Scheme 3 in Table 2).

Table 1. The results of the proposed decision tree.

\begin{tabular}{cl}
\hline \multicolumn{1}{c}{ Indicator } & \multicolumn{1}{c}{ Description } \\
\hline Total Frequency & $\begin{array}{l}\text { Training Data: } 110 \\
\text { Validation: } 21\end{array}$ \\
\hline Classification Error Rate & $\begin{array}{l}\text { Training Data: 37.8\% } \\
\text { Validation: } 29 \%\end{array}$ \\
\hline Variable Importance & $\begin{array}{l}\text { Warehousing } \\
\text { Packaging }\end{array}$ \\
\hline
\end{tabular}

\subsection{Managerial implications}

This research looked at the related elements of the original text to depart from the research results on the proposed business analytics, to determine the required market strategy for the handling of supply chain halal food supply chains. Plans are further developed on the basis of the hypotheses RV (Cao and Zhang, 2011; Gold et al., 2010) and NRBV (Hart, 1995; Hart and Dowell, 2011).

Table 2. The schemes for sustainability in halal food supply chains.

\begin{tabular}{|c|c|c|c|c|}
\hline Scheme & Nodes & Rule & Accuracy & Coverage Rate \\
\hline A1 & 3 & $\begin{array}{l}\text { if Warehousing is ONE of: } 1 \\
\text { then } \\
\text { Number of Observations }=21 \\
\text { Predicted: } y=1=0.57 \\
\text { Predicted: } y=0=0.43\end{array}$ & $57 \%$ & $32.70 \%$ \\
\hline A2 & 4 & $\begin{array}{l}\text { if Warehousing is ONE of: } 0 \text { or MISSING and Packaging is ONE of: } 0 \text { or } \\
\text { MISSING then Number of Observations }=41 \text { Predicted: } y=1=0.59 \\
\text { Predicted: } y=0=0.41\end{array}$ & $59 \%$ & $38.30 \%$ \\
\hline A3 & 5 & $\begin{array}{l}\text { if Warehousing is ONE of: } 0 \text { or MISSING and Packaging is ONE OF: } 1 \text { then } \\
\text { Number of Observations }=48 \text { Predicted: } y=0.55 \\
\text { Predicted: } y=0=0.45\end{array}$ & $55 \%$ & $29 \%$ \\
\hline
\end{tabular}


3.3.1 Automatic warehousing to lead operational efficiency

The analysis of the proposal that automated storage is a crucial factor in organizational performance. Automated warehousing can also boost the effective halal food chain and keep halal food saucers and hygienic in the original unstructured data collection (Nor et al., 2016). Hygiene and quality are necessary for the management of the food supply chain by food producers to provide food healthy and suited to consumption Food Hygiene and Quality. Another initial unstructured data collection has shown that DB Schenker, a logistics multinational corporation in Malaysia, has successfully applied automated warehousing for non-halal loads separating from the transport and storing of the cargo, has high sanitation standards both in transport and in warehousing (OpenText, 2018).

\subsubsection{Utilize eco-friendly for halal packaging to realize tayyib and halal food}

The goal for the safeguarding and improvement of the quality of life is the implementation, in the food industry, of Tayyib (clean and pure) as a public health priority. In order to protect against food-related illnesses, Tayyib considers food safety, food additives, pollution and pesticide residues (Ambali and Bakar, 2014). Tayyib also fulfils Sharia principles well, enriching communities with theological, moral, and human values. Likewise, as the Tayyib principle is applied to animals, the effect on animal health is a positive one.

The research outcome of the market analytics suggested indicates that eco-packaging will make a food supply chain effective in achieving sustainable environmental growth in line with NRBV theory. One of the original unbuilt data collections states that MM Karton manufactured environmental-friendly halal food packaging, replacing plastic and certified halal (QY Research, 2020). Moreover, in order to successfully replace the number of the additive polymer as raw materials for halal packaging, Cardia Bio-Plastic developed bio-hybrid resins as the based raw materials and received halal certification (Halal Focus, 2015).

\section{Conclusion}

The use of big data as one of the primary sources to get an overview of the latest developments in the field of sustainability has become a common practice today. This study uses big data from various databases of leading journals and websites related to halal food supply chain management. The results of the analysis found that to fulfil the principles of sustainability in halal food supply chain management, automatic warehousing is a crucial factor to support operational efficiency. In addition, the use of automatic warehousing is also effective in maintaining the quality and hygiene of halal food.

The second important factor is eco-friendly packaging for halal food. The use of environmentally friendly packaging technology is an important indicator to support the entire sustainable supply chain process for the halal food industry. Further studies must be able to include other primary sources in different languages, such as Arabic, Malay, or Indonesian. This is because a lot of important information related to the issue of sustainability in the field of halal food supply chain management is written in these 3 languages on various websites and journals so that further studies will be more comprehensive.

\section{Conflict of interest}

The authors declare no conflict of interest.

\section{References}

Ab Talib, M.S. and Mohd Johan, M.R. (2012). Issues in halal packaging: A conceptual paper. International Business and Management, 5(2), 94-98. http:// doi.org/10.3968/j.ibm.1923842820120502.1080

Alam, S. and Mohamed Sayuti, N. (2011), Applying the Theory of Planned Behavior (TPB) in halal food purchasing, International Journal of Commerce and Management, 21(1), 8-20. https:// doi.org/10.1108/10569211111111676

Alghamdi, R. and Alfalqi, K. (2015). A survey of topic modeling in text mining. International Journal of Advance Computer Science and Applications, 6(1), 147-153. https://doi.org/10.14569/ IJACSA.2015.060121

Al-Ghwayeen, W.S. and Abdallah, A.B. (2018). Green supply chain management and export performance. Journal of Manufacturing Technology Management, 29(7), 1233-1252. https:// doi.org/10.1108/JMTM-03-2018-0079

Ali, M.H. and Suleiman, N. (2016). Sustainable food production: Insights of Malaysian halal small and medium sized enterprises. International Journal of Production Economics, 181(PB), 303-314. https:// doi.org/10.1016/j.ijpe.2016.06.003

Ali, M.H., Tan, K.H. and Ismail, M.D. (2017). A supply chain integrity framework for halal food. British Food Journal, 119(1), 20-38. https:// doi.org/10.1108/BFJ-07-2016-0345

Ambali, A.R. and Bakar, A.N. (2014). People's awareness on halal foods and products: potential issues for policy-makers. Procedia-Social and Behavioral Sciences, 121(1), 3-25. https:// 
doi.org/10.1016/j.sbspro.2014.01.1104

Barratt, M. (2004). Understanding the meaning of collaboration in the supply chain. Supply Chain Management: An International Journal, 9(1), 30-42. https://doi.org/10.1108/13598540410517566

Benis, K. and Ferrao, P. (2017). Potential mitigation of the environmental impacts of food systems through urban and peri-urban agriculture (UPA) - a life cycle assessment approach. Journal of Cleaner Production, 140(2), 784-795. https:// doi.org/10.1016/j.jclepro.2016.05.176

Bonne, K., Vermeir, I., Bergeaud-Blackler, F. and Verbeke, W. (2007). Determinants of halal meat consumption in France. British Food Journal, 109 (5), 367-386. https:// doi.org/10.1108/0070700710746786

Brants, T. (2003). Natural Language Processing in Information Retrieval. USA: CRC Press. https:// doi.org/10.1081/e-elis3-120008664

Camanzi, L., Alikadic, A., Compagnoni, L. and Merloni, E. (2017). The impact of greenhouse gas emissions in the EU food chain: a quantitative and economic assessment using an environmentally extended inputoutput approach. Journal of Cleaner Production, 157, 168-176. https://doi.org/10.1016/ j.jclepro.2017.04.118

Cao, M. and Zhang, Q. (2011). Supply chain collaboration: Impact on collaborative advantage and firm performance. Journal of Operations Management, 29(3), 163-180. https:// doi.org/10.1016/j.jom.2010.12.008

Chen, M.-C., Chen, L.-S., Hsu, C.-C. and Zeng, W.-R. (2008). An information granulation based data mining approach for classifying imbalanced data. Information Sciences, 178(6), 3214-3227. https:// doi.org/10.1016/j.ins.2008.03.018

Chopra, S. and Meindl, P. (2015). Supply Chain Management: Strategy, Planning, and Operation, $6^{\text {th }}$ ed. Boston, USA: Pearson.

Farouk, M.M., Pufpaff, K.M. and Amir, M. (2016). Industrial halal meat production and animal welfare: A review. Meat Science, 120, 60-70. https:// doi.org/10.1016/j.meatsci.2016.04.023

Gold, S., Seuring, S. and Beske, P. (2010). Sustainable supply chain management and inter-organizational resources: a literature review. Corporate Social Responsibility and Environmental Management, 17 (4), 230-245. https://doi.org/10.1002/csr.207

Hart, S.L. (1995). A natural-resource-based view of the firm. Academy of management review, 20(4), 9861014. https://doi.org/10.5465/amr.1995.9512280033

Hart, S.L. and Dowell, G. (2011). Invited editorial: A natural-resource-based view of the firm: Fifteen years after. Journal of Management, 37(5), 14641479. https://doi.org/10.1177/0149206310390219

Karia, N. and Asaari, M.H.A.H. (2016). Halal value creation: Its role in adding value and enabling logistics service. Production Planning and Control, 27(9), 677-685. https:// doi.org/10.1080/09537287.2016.1166276

Karl, A., Wisnowski, J. and Rushing, W.H. (2015). A practical guide to text mining with topic extraction. Wiley Interdiscip. WIREs Computational Statistics, 7 (5), 326-340. https://doi.org/10.1002/wics. 1361

Kou, G. and Peng, Y. (2015). An application of latent semantic analysis for text categorization. International Journal of Communications and Control, 10(3), 357-369. https://doi.org/10.15837/ ijccc.2015.3.1923

La Scalia, G., Nasca, A., Corona, O., Settanni, L. and Micale, R. (2017). An innovative shelf life model based on smart logistic unit for an efficient management of the perishable food supply chain. Journal of Food Process Engineering, 40(1), e12311. https://doi.org/10.1111/jfpe.12311

Leat, P. and Revoredo-Giha, C. (2013). Risk and resilience in agri-food supply chains: the case of the ASDA PorkLink supply chain in Scotland. Supply Chain Management: An International Journal, 18 (2), 219-231. https:// doi.org/10.1108/13598541311318845

Manning, L. and Soon, J.M. (2014). Developing systems to control food adulteration. Food Policy, 49(1), 2332. https://doi.org/10.1016/j.foodpol.2014.06.005

Mashechkin, I.V., Petrovskiy, M.I., Popov, D.S. and Tsarev, D.V. (2011). Automatic text summarization using latent semantic analysis. Programming and Computer Software, 37, 299-305. https:// doi.org/10.1134/S0361768811060041

Nor, M.R.M., Latif, K., Ismail, M.N. and Nor, M.N.M. (2016). Critical success factors of halal supply chain management from the perspective of Malaysian halal food manufacturers. Arabian Journal of Business and Management Review (Nigerian Chapter), 4, 123. https://doi.org/10.12816/0031515

Nuhoff-Isakhanyan, G., Wubben, E.F. and Omta, S.W.F. (2016). Sustainability benefits and challenges of inter-organizational collaboration in Bio-Based business: A systematic literature review. Sustainability, 8(4), $307 . \quad$ https:// doi.org/10.3390/su8040307

Oliveira, S. and Seok, S.C. (2005). A multi-level approach for document clustering. In Sunderam, V.S., Van Albada, G.D., Sloot, P.M.A. and 
Dongarra, J.J. (Eds.) Computational Science - ICCS 2005. Lecture Notes in Computer Sciences. Vol. 3514, p. 204-211. Berlin, Germany: Springer. https:// doi.org/10.1007/11428831_26

OpenText. (2018). DB Schenker relies on OpenText Trading Grid to communicate internally, meet trading partner expectations. Retrieved from https:// www.opentext.com/file_source/OpenText/ Customers/en_US/PDF/schenker-15-en.pdf

QY Research. (2020). Global Halal Packaging Market Share 2020 - Industry Analysis by Latest Trends and Companies. Retrieved Orbis Chem Reports website: https://www.orbischemreports.com/global-halalpackaging-market-share-2020-industry-analysis-bylatest-trends-and-companies/76824/

Soon, J.M., Chandia, M. and Regenstein, J.M. (2017). Halal integrity in the food supply chain. British Food Journal, 119(1), 39-51. https://doi.org/10.1108/BFJ04-2016-0150

Salama (2014). State of Global Islamic Economy Report and Indicator 2014/2015. Retrieved from Halal Focus website: https://halalfocus.net/state-of-globalislamic-economy-report-indicator-20142015/

Tan, M.I.I., Razali, R.N. and Husny, Z.J. (2012). The Adoption of Halal Transportations Technologies for Halal Logistics Service Providers in Malaysia. International Journal of Mechanical, Industrial Science and Engineering, 5(3), 451. https:// doi.org/10.5281/zenodo. 1328454

Wang, E.S.T. (2015). Effect of food service-brand equity on consumer-perceived food value, physical risk, and brand preference. British Food Journal, 117(2), 553-564. https://doi.org/10.1108/BFJ-09-2013-0260

Zhai, C. and Massung, S., (2016). Text data management and analysis: a practical introduction to information retrieval and text mining. New York, USA: Association for Computing Machinery and Morgan and Claypool. https://doi.org/10.1145/2915031

Zulfakar, M.H., Anuar, M.M. and Ab Talib, M.S. (2014). Conceptual framework on halal food supply chain integrity enhancement. Procedia-Social and Behavioral Sciences, 121, 58-67. https:// doi.org/10.1016/j.sbspro.2014.01.1108 